\title{
Intravenous Glucose Tolerance, Insulin, Glucose, and Free Fatty Acid Levels after Myocardial Infarction
}

\author{
S. P. ALLISON,* M.B., M.R.C.P. ; M. J. CHAMBERLAIN, $\dagger$ M.B., M.R.C.P. ; PAMELA HINTON, $\ddagger$ M.B., M.R.C.P.
}

British Medical Fournal, 1969, 4, 776-778

\begin{abstract}
Summary : Glucose tolerance tests performed on 12 patients within 15 hours of myocardial infarction and repeated two to four weeks later showed failure of insulin secretion, hyperglycaemia, glucose intolerance, and high free fatty acid levels. More pronounced changes were found in patients with cardiogenic shock. These findings suggest that the therapeutic use of potassium, glucose, and insulin should be re-evaluated.
\end{abstract}

\section{Introduction}

Failure of insulin response to injected glucose during surgery and in the acute phase of myocardial infarction was described in a preliminary communication (Allison et al., 1967). The same phenomenon was observed in burned patients (Allison, Hinton, and Chamberlain, 1968). Earlier studies suggested that the degree of suppression of insulin secretion, glucose intolerance, and raised free fatty acids in acute illness is proportional to the severity of the stress (Allison et al., 1968, 1969). Dykes et al. (1969) reported four cases of cardiogenic shock following myocardial infarction in which tolbutamide failed to cause a significant rise in plasma insulin levels.

The purpose of the present study was to confirm previous observations and to assess the difference between the metabolic changes in patients with cardiogenic shock and those in less severe cases.

\section{Patients and Methods}

Of the 12 patients studied four (group 1) were suffering from cardiogenic shock (systolic blood pressure $<100 \mathrm{~mm}$. Hg, with signs of severe vasoconstriction) and eight (group 2) had a less severe clinical picture (systolic blood pressure $<100 \mathrm{~mm}$. Hg and no clinical signs of shock). The age range in group 1 was 57 to 73 (mean 65) years and in group 240 to 72 (mean 53) years. In each patient a standard $25-\mathrm{g}$. intravenous glucose tolerance test (Samols and Marks, 1965) was performed within 15 hours of the onset of symptoms and repeated two to four weeks later. The acute and follow-up studies were compared in terms (1) of the basal levels of blood sugar, plasma insulin, and free fatty acids ; (2) of the $K$ value or slope of the glucose tolerance curves ; (3) of insulin response to the injected ghucose ; and (4) of the fall in plasma free fatty acid levels after glucose injection. A comparison was also made between the results obtained in groups 1 and 2 . None of the patients had taken food within six hours of the acute study. The follow-up study was performed after an overnight fast.

Forearm venous blood samples were taken before and at 2 , $5,10,20,30,40,50$, and 60 minutes after intravenous injection of $25 \mathrm{~g}$. of glucose in $50 \%$ solution into the other arm. The samples were placed immediately in the refrigerator at $4^{\circ} \mathrm{C}$. Blood samples for blood sugar tests were taken into fluoride tubes and estimated within 24 hours by the Neocuprin autoanalyser technique. The reproducibility of this technique is within $2 \%$. Plasma insulin was measured in triplicate by the method of Hales and Randle (1963). Samples were taken into sodium heparin tubes. The plasma was then separated by centrifugation and stored at $-20^{\circ} \mathrm{C}$. until it could be assayed. Samples from acute and follow-up glucose tolerance tests from the same patient were estimated in the same assay. The accuracy of the technique may be gauged by the fact that assays of insulin levels from specimens of a plasma pool measured over

\footnotetext{
* M.R.C. Clinical Research Fellow, Department of Medicine, University of Birmingham. Present address: Department of Biochemistry, University of Bristol, Bristol' 8

+ Consulant Physician, Dudley Road Hospital, Birmingham 18.

† Medical Registrar, the Birmingham Accident Hospital, Birmingham 15.
}
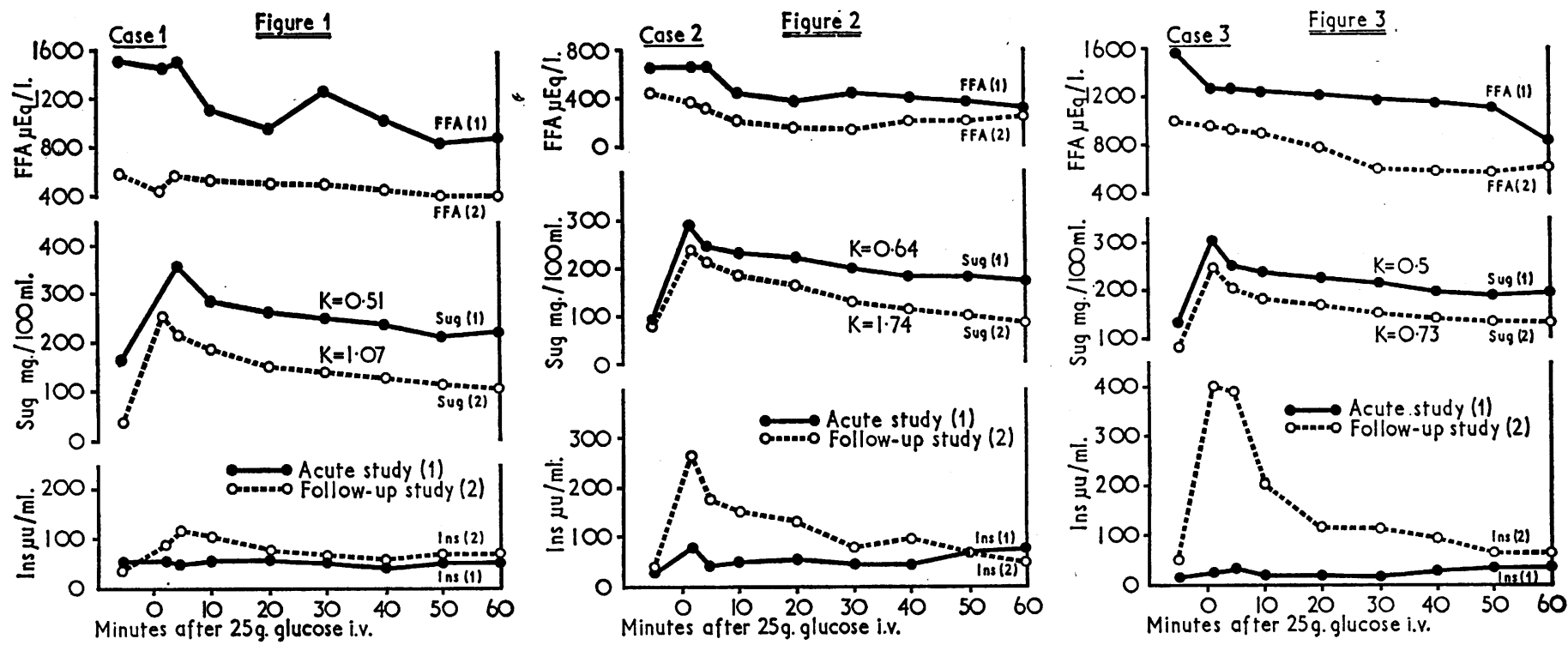

Plasma insulin infarction. The values in the acute study $(x-x)$ are compared with those in the follow-up study (O-O). Case 1 , man aged 67 . Case 2 , man aged 38 . Case 3 , man aged 52. 
a period of three months gave a coefficient of variation of $8.5 \%$. Free fatty acids were estimated colorimetrically by Duncombe's (1963) method, following extraction by the method of Dole and Meinertz (1960). Blood samples were treated in the same way as for insulin except that analysis of the separated plasma was carried out within 24 hours. The reproducibility of paired samples was within $5 \%$.

\section{Results}

The results were qualitatively the same in every patient. Comparison of the acute study with the follow-up study showed the following differences in every case: higher basal values of blood sugar and plasma free fatty acids, lower $K$ values in the diabetic range $(<1)$, failure of insulin response to glucose, and a diminished fall in free fatty acid levels after glucose infusion. The results from one patient of group 1 (Fig. 1) and two patients of group 2 (Figs. 2 and 3 ) are shown as examples. Two patients in group 1 and one patient in group 2 died before a follow-up test could be performed. In all of these patients there was little or no insulin response to glucose. In three out of the nine patients on whom follow-up tests were carried out there was a diabetic glucose tolerance test ( $K$ value $<0 \cdot 1)$ with a normal or excessive insulin response (in comparison with a series of normal subjects (Fig. 3).

The mean level of glucose, the percentage rise in plasma insulin, and the percentage fall in free fatty acids in groups 1 and 2 are compared in the Table. The means (to the nearest whole number) are expressed \pm 1 standard deviation. The results of Student's $t$ test applied to the values at each time during the glucose tolerance test are expressed as a " $P$ value." The differences in blood sugar levels were significant at all times. The differences in percentage plasma insulin rise were significant at 2, 5, and 10 minutes, as were the differences in percentage fall in free fatty acid levels at $30,40,50$, and 60 minutes.

The differences between the mean basal plasma insulin levels (group 1, 26 $\pm 12 \mu \mathrm{u} . / \mathrm{ml}$. ; group 2, $27 \pm 19 \mu \mathrm{u} . / \mathrm{ml}$.) and free fatty acid levels (group 1, 1,141 $\pm 461 \mathrm{mEq} / 1$. ; group 2, 1,077 \pm $364 \mathrm{mEq} / \mathrm{l}$.) were not statistically significant $(P>0.05)$.

\section{Discussion}

These results confirm our previous observation of suppression of insulin seoretion after myocardial infarction, and also suggest, despite the small numbers studied, that the extent of the changes in insulin secretion, basal glucose levels, glucose tolerance, and the lack of fall in free fatty acid levels after glucose injection may be proportional to the severity of the illness. This is comparable with the changes in burned patients which relate in degree to the area of burned skin surface (Allison et al., 1968).

Suppression of insulin secretion in the acute phase of myocardial infarction is probably caused by the hypersecretion of adrenaline known to occur in this condition (Valori et al., 1967). Kosaka et al. (1964), Porte et al. (1966), and Miller and Soeldner (1969) showed that infusion of adrenaline suppresses insulin secretion in response to glucose in normal humans and animals. Coore and Randle (1964) and Loubatières et al. (1965) showed suppression of insulin release from isolated pancreatic tissue in the presence of adrenaline. The results of Dykes et al. (1969), who showed failure of tolbutamide to cause a significant rise in plasma insulin in patients with cardiogenic shock, are in accord with those of Porte et al. (1966), who showed that tolbutamide did not reverse the insulin suppression produced by adrenaline in normal subjects. It would be of interest to test the effect of $\alpha$-blockade on insulin secretion in cardiogenic shock, since $\alpha$-blockers are used therapeutically in this condition and Porte et al. showed suppression of insulin release to be an $\alpha$-adrenergic effect.

Hyperglycaemia in non-diabetic patients after myocardial infarction has been described by many workers. Ellenberg et al. (1952) showed in their study that hyperglycaemia was more pronounced in the shocked than in the non-shocked patients. They postulated that hyperglycaemia following myocardial infarction was due to mobilization of glycogen by adrenaline and to gluconeogenesis under the influence of adrenocortical hormones. It is clear from the present study that an important cause of hyperglycaemia under these circumstances is suppression of insulin release, so that adrenaline and cortisol are able to act unopposed. Though there is no significant difference between the basal levels of plasma insulin in the two groups, an important difference becomes apparent if these values are taken in relation to the much higher basal blood sugars in group 1.

Diminished insulin secretion may also help to account for the high serum free fatty acid levels observed after myocardial infarction by Oliver et al. (1968). Those authors showed that a higher percentage of shocked patients had free fatty acid levels greater than $1,200 \mathrm{mEq} / 1$. when compared with nonshocked patients. Because of the wide scatter of free fatty acid values between individuals it is not possible to demonstrate differences in basal free fatty acid levels between such small groups as in this study. The clear difference between groups 1 and 2 in the percentage fall in free fatty acid after glucose injection (see Table) probably reflects not only the greater catecholamine secretion in group 1 but also the smaller insulin secretion in this group.

Insulin resistance following myocardial infarction has not been satisfactorily explained. Vallance-Owen and Ashton (1963) showed an increased level of synalbumin in 19 out of 28 patients convalescing from myocardial infarction, but their results await confirmation. Ross et al. (1966) described insulin resistance after abdominal surgery and showed that this was not related to cortisol and growth hormone hypersecretion. It is conceivable that some of these patients have a high level of free fatty acids contributing to insulin resistance (Randle et al., 1963). We were not able to test this in our small group.

Comparison of Groups 1 and 2

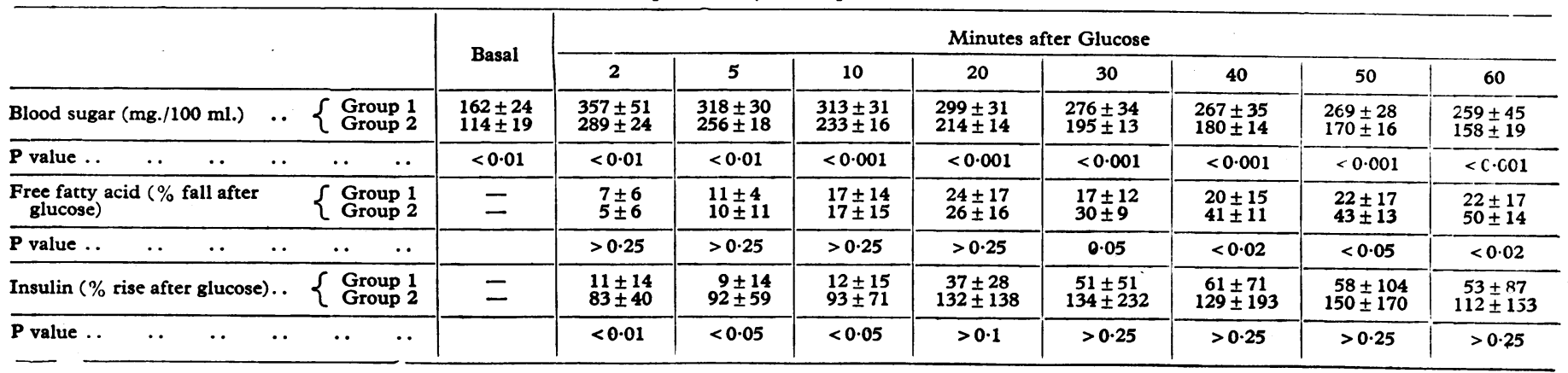


Therapeutic implications of these results are controversial: Owen et al. (1969) showed that following experimental coronary artery occlusion the ischaemic area of myocardium depends on glycolysis for its energy metabolism. They point out that it might be important to provide adequate supplies of glucose for survival of the ischaemic area of muscle surrounding an infarct. Since heart muscle is insulin-sensitive and we have demonstrated suppression of insulin secretion in acute myocardial infarction, it seems logical to give insulin as well.

Oliver et al. (1968) and Kurien et al. (1969) showed a correlation between high levels of free fatty acids and the incidence of arrhythmias after myocardial infarction. If these are cause and effect, as seems likely from those authors' evidence, rather than two manifestations of the greater sympathetic activity in severe cases, then glucose and insulin would be useful in lowering free fatty acid levels.

A recent letter from Sodi-Pallares et al. (1969) pointed out that trials to test their regimen of potassium, glucose, and insulin in acute myocardial infarction have either not used the same route of administration or have not used anywhere near the same dosage of these substances which they advocate (M.R.C. Working Party, 1968 ; Pentecost et al., 1968). We have used large doses of insulin (200 units daily) and $50 \%$ glucose ( 1 litre daily) in the treatment of the "sick cell syndrome" of burned patients and of patients with chronic congestive cardiac failure (Hinton et al., in preparation). This measure has produced a rapid return of electrolyte biochemistry to normal. It is conceivable that such a mechanism might operate in a localized area of ischaemic myocardium and that the potassium, glucose, and insulin regimen of Sodi-Pallares et al. should be evaluated with an entirely different order of insulin and glucose dosage to that previously used in this country.

We thank Miss Ann Unitt and Mrs. Christine Haynes for technical help; Professor T. P. Whitehead and the department of biochemistry for measuring blood sugar levels; Dr. R. F. Fletcher for his encouragement and helpful criticism; Professor W. Melville Arnott for his support; and Dr. P. H. Davison, Professor John Bishop, and Dr. Gordon Cumming for allowing us to study patients under their care. We also thank the Medical Research Council for supporting one of us (S. P. A.) and financing purchase of equipment.

Requests for reprints should be sent to S. P. Allison, Department of Biochemistry, University of Bristol, Bristol.

\section{REFERENCES}

Allison, S. P., Hinton, Pamela, and Chamberlain, M. J. (1968). Lancet, 2, 1113. Allison, S. P., Prowse, K., and Chamberlain, M. J. (1967). Lancet, 1,

Allison, S. P., Tomlin, P. J., and Chamberlain, M. J. (1969). British Fournal of Anaesthesia, 41, 588 .

Coore, H. G., and Randle, P. J. (1964). Biochemical fournal, 93, 66. Dole, V. P., and Meinertz, H. (1960). Journal of Biological Chemistry, 235, 2595 .

Duncombe, W. G. (1963). Biochemical fournal, 88, 7.

Dykes, J. R. W., Saxton, C., and Taylor, S. H. (1969). British Medical fournal, 2, 490.

Ellenberg, M., Osserman, K. E., and Pollack, H. (1952). Diabetes, 1,

16. C. N., and Randle, P. J. (1963). Biochemical fournal, 88, 137.

Kosaka, K., et al. (1964). Endocrinology, 75, 9.

Kosaka, K., et al. (1964). Endocrinology, 75, 9.

Kurien, V. A., Yates, P. A., and Oliver, M. F. (1969).
Loubatieres, A., et al. (1965). Diabetologia, $1,13$.

Loubatierres, A., et al. (1965). Diabetologia, 1, 13.

Medical Research Council Working Party (1968). Lancet, 2,

Oliver, M. F., Kurien, V. A., and Greenwood, T. W. (1968). Lancet, 1, 710.

Owen, Patricia, Thomas, M., and Opie, L. (1969). Lancet, 1, 1187.

Pentecost, B. L., Mayne, N. M. C., and Lamb, P. (1968). Lancet, 1,

946. fournal of Clinical Investigation, 45, 228.

Randle, P. J., Garland, P. B., Hales, C. N., and Newsholme, E. A. (1963). Lancet, 1,785.

Ross, H., Johnston, I. D. A., Welborn, T. A., and Wright, A. D. (1966). Lancet, 2, 563.

Samols, E., and Marks, V. (1965). Lancet, 1, 462. Lancet, 1,1315 .
Lallares, D., de

Vallance-Owen, J., and Ashton, W. L. (1963). Lancet, 1, 1226.

Valori, C., Thomas, M., and Shillingford, J. P. (1967). Lancet, 1, 127.

\title{
Intraluminal Transport of Iron from Stomach to Small-intestinal Mucosa
}

\author{
A. JACOBS,* M.D., M.R.C.PATH.; P. M. MILES, $\dagger$ B.SC.
}

Summary : Inorganic iron rarely exceeds $10^{-4}$ molar $N$ concentration in the stomach after a meal. Natural sugars, ascorbic acid, citric acid, and amino-acids form iron complexes, and if they are present in the meal complexing occurs when the gastric contents are neutralized. In their absence an iron complex is formed with gastric mucopolysaccharide, which acts as a carrier, stable at neutral $p H$. Iron can be detached from this carrier at neutral $p H$ by some low molecular weight substances, of which citric acid, ascorbic acid, and cysteine are particularly effective at low concentrations. Under normal circumstances most of the iron released from food in the stomach becomes bound to the mucopolysaccharide carrier.

* Reader in Haematology.

+ Research Assistant.

Welsh National School of Medicine, Cardiff

\section{Introduction}

The existence of specific gastric factors which influence iron absorption has been postulated by several workers. Some have suggested that gastric juice contains a substance which potentiates inorganic iron absorption and that the level of absorption is regulated by variation in the amount secreted (Koepke and Stewart, 1964; Murray and Stein, 1968). Davis, Luke, and Deller (1966) measured gastric iron binding in vitro and found an iron-binding substance of high molecular weight in the gastric juice of healthy subjects, which they called "gastroferrin." Gastroferrin was absent or greatly reduced in amount in patients with idiopathic haemochromatosis and in irondeficiency anaemia (Luke, Davis, and Deller, 1967). They assumed that its normal action was to inhibit iron absorption.

Neither of these hypotheses has been supported by the observations of other investigators. Mignon et al. (1965) were 